\title{
A case of ectopic ACTH syndrome treated with intermittent administration of dopamine agonists
}

\author{
Satoru Sakihara ${ }^{\dagger}$, Kazunori Kageyama, Satoshi Yamagata, Ken Terui, \\ Makoto Daimon and Toshihiro Suda ${ }^{+}$ \\ Department of Endocrinology and Metabolism, Hirosaki University Graduate School of Medicine, \\ 5 Zaifu-cho, Hirosaki, Aomori 036-8562, Japan \\ ${ }^{\dagger} S$ Sakihara and T Suda are now at Aomori Rosai Hospital, 1 Minamigaoka, Shirogane-machi, \\ Hachinohe 031-8551, Japan
}

\author{
Correspondence \\ should be addressed \\ to K Kageyama \\ Email \\ kkageyama@hkg.odn.ne.jp
}

\section{Summary}

ACTH-dependent Cushing's syndrome includes Cushing's disease and ectopic ACTH syndrome (EAS). The differential diagnosis of Cushing's disease from EAS in cases of ACTH-dependent Cushing's syndrome is a challenging problem. We report here a case of EAS with an unknown source of ACTH secretion. Extensive imaging procedures, involving computed tomography (neck to pelvis), pituitary magnetic resonance imaging, and whole-body ${ }^{18} \mathrm{~F}$-fluorodeoxyglucose-positron emission tomography, failed to reveal the source of ACTH secretion. Intermittent administration of bromocriptine, a short-acting and nonselective dopamine agonist, has afforded adequate suppression of plasma ACTH and cortisol levels over the long term.

\section{Learning points}

- Tumor excision is the primary treatment for EAS. However, when surgery is impossible, medical therapy is needed to treat hypercortisolism.

- In cases where the source of ACTH secretion is unknown, inhibitors of steroidogenesis, such as metyrapone, mitotane, ketoconazole, and etomidate, are mostly used to suppress cortisol secretion.

- Medications that suppress ACTH secretion are less effective, therefore less popular, as standard treatments.

- In the present case, short-term treatment with dopamine agonists was effective for the long-term suppression of both ACTH and cortisol levels.

\section{Background}

Cushing's syndrome is characterized by signs and symptoms resulting from chronic glucocorticoid excess. Adrenocorticotropic hormone (ACTH)-dependent Cushing's syndrome includes Cushing's disease and ectopic ACTH syndrome (EAS), with the latter resulting from an extrapituitary ACTHsecreting tumor such as a small-cell lung carcinoma, pheochromocytoma, or bronchial or thymic carcinoid (1). The differential diagnosis of Cushing's disease from EAS in cases of ACTH-dependent Cushing's syndrome is a challenging problem in clinical endocrinology because the findings for Cushing's disease partially overlap with those of EAS (2). In addition, localization of the tumor in EAS often complicates its surgical removal, which is the first-line treatment for EAS. In cases where the source of ACTH secretion is unknown, inhibitors of steroidogenesis, such as metyrapone, mitotane, ketoconazole, and etomidate, are mostly used to suppress cortisol secretion (3).

We present the case of EAS, for which extensive imaging procedures failed to reveal the source of ACTH secretion but dopamine agonists provided long-lasting control of hypercortisolemia. 

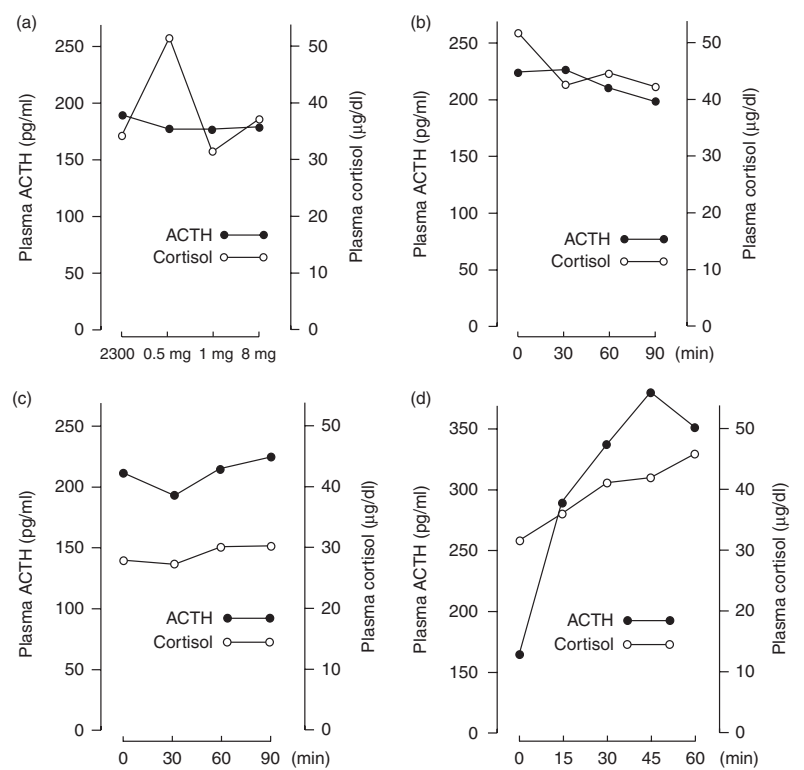

Figure 1

Hormone loading test results (on first administration). (a) Overnight dexamethasone suppression test (per os at $2300 \mathrm{~h}$ ); (b) desmopressin test ( $4 \mu \mathrm{g}$, i.v. bolus); (c) human corticotropin-releasing hormone test (100 $\mu \mathrm{g}$, i.v. bolus); and (d) growth hormone-releasing peptide 2 test $(100 \mu \mathrm{g}$, i.v. bolus). ACTH, adrenocorticotropic hormone.

\section{Case presentation}

A 65-year-old Japanese woman was referred for evaluation of hypokalemia. On admission, her body weight was $57.0 \mathrm{~kg}$ and BMI was $27.5 \mathrm{~kg} / \mathrm{m}^{2}$. She had no regular alcohol intake. She had no symptoms such as lethargy and change in mood. She had been diagnosed with type 2 diabetes mellitus and hypertension 1 year before, and controlled with diet and an antihypertensive agent respectively. She was still hypertensive $(171 / 85 \mathrm{mmHg})$ and had a moon face, central obesity, buffalo hump, purple striae, thin skin, and proximal myopathy.

\section{Investigation}

All endocrine examinations were performed according to clinical guidelines, and the patient provided informed consent for the tests. The plasma basal ACTH level was $225 \mathrm{pg} / \mathrm{ml}(49.6 \mathrm{pmol} / \mathrm{l})$ and the plasma cortisol level was $54.8 \mu \mathrm{g} / \mathrm{dl}(1512.5 \mathrm{nmol} / \mathrm{l})$. Excretion of urinary free cortisol was $1099 \mu \mathrm{g} /$ day $(3033.2 \mathrm{nmol} /$ day). As the laboratory data suggested ACTH-dependent hypercortisolism, further tests were performed to determine autonomic secretion of ACTH. They revealed i) incomplete suppression of plasma cortisol levels ( $>5 \mu \mathrm{g} / \mathrm{dl}$
$(133.5 \mathrm{nmol} / \mathrm{l}))$ in a low-dose $(0.5 \mathrm{mg})$ overnight dexamethasone suppression test (DST), ii) high plasma cortisol levels ( $>5 \mu \mathrm{g} / \mathrm{dl}(133.5 \mathrm{nmol} / \mathrm{l}))$ during nighttime sleep, and iii) no response of plasma ACTH levels to the desmopressin (DDAVP) test (Fig. 1). Additional endocrine examinations demonstrated the following: no response of plasma ACTH levels by the human corticotropin-releasing hormone (hCRH) test; an exaggerated response of plasma ACTH levels by the growth hormone-releasing peptide 2 (GHRP2) test; little suppression of plasma cortisol levels (less than half the basal level) in a high-dose $(8 \mathrm{mg})$ overnight DST; and no clear pituitary adenoma and no shift of pituitary stalk on MRI with Gd-DTPA enhancement (Fig. 2). A selective venous sampling test was also performed, and catheterization of only the right side was successful. As plasma ACTH levels increased after the GHRP2 test, but not after the hCRH test, sampling was followed by the administration of GHRP2. The results of cavernous sinus sampling were considered diagnostic for an ectopic source of ACTH production because the basal ratio (central:peripheral ratio before the test) was 1.16 , lower than the expected 2.0, and the peak ratio after GHRP2 administration was 1.05 (Table 1). However, CT scans from neck to pelvis failed to detect localization of an ectopic source, as did FDG-PET. Both plasma ACTH and cortisol levels were weakly decreased by the test dose of somatostatin analog octreotide and potently suppressed by the dopamine agonist bromocriptine (Fig. 3).

\section{Treatment}

Based on a response to the test dose of bromocriptine, the patient was treated with selective dopamine agonist cabergoline at $0.25 \mathrm{mg} /$ day (Fig. 4), which was gradually increased to $0.5 \mathrm{mg} / \mathrm{day}$ and maintained plasma ACTH and cortisol levels, at lower normal range for 40 days (Fig. 4).
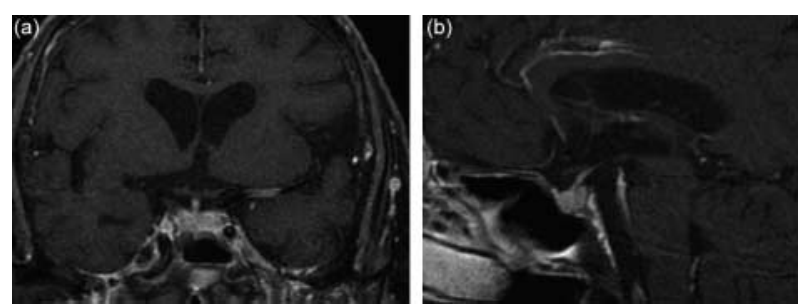

Figure 2

Coronal (a) and sagittal (b) MRI scans with Gd-DTPA enhancement of the pituitary. 
Table 1 Cavernous sinus sampling.

\begin{tabular}{lccc}
\hline & \multicolumn{2}{c}{ ACTH $(\mathrm{pg} / \mathrm{ml})$} \\
\cline { 2 - 3 } & & Basal & After GHRP2 \\
Inferior vena cava & 174 & 348 \\
Right jugular vein & 184 & 389 \\
Right inferior petrosal sinus & 181 & 370 \\
Right cavernous sinus & 201 & 366 \\
\hline
\end{tabular}

ACTH, adrenocorticotropic hormone; GHRP2, GH-releasing peptide.

\section{Outcome and follow-up}

Cabergoline was discontinued due to adrenal failure. Both basal plasma ACTH and cortisol levels stayed within normal limits and showed normal responses to hormonal tests for more than 1 year (Fig. 5). However, 16 months later, high glucose, ACTH, and cortisol levels were again observed. FDG-PET revealed a lesion in the right lobe of the thyroid. It was resected and histologically diagnosed as papillary carcinoma. However, it showed no ACTH immunostaining. Short-term treatment with cabergoline normalized plasma ACTH and cortisol levels for 1 year, but thereafter glucose, ACTH, and cortisol levels were once again increased. GH and prolactin levels were 0.11 and $5.2 \mathrm{ng} / \mathrm{ml}$ respectively. Fasting blood glucose, LDL cholesterol, and triglyceride levels were 156,97 , and $95 \mathrm{mg} / \mathrm{dl}$ respectively.

As we considered that a short-acting dopamine agonist might be enough to control cortisol levels, the patient was initially treated with $2.5 \mathrm{mg}$ bromocriptine two times per week, followed by $2.5 \mathrm{mg}$ bromocriptine three times per week, together with replacement of hydrocortisone (5-10 mg/day). Thereafter, plasma ACTH and cortisol levels have been controlled within normal limits for almost 1 year (Fig. 6). After treatment, fasting blood glucose, LDL cholesterol, and triglyceride levels were 86,75 , and $105 \mathrm{mg} / \mathrm{dl}$ respectively.

\section{Discussion}

The findings for Cushing's disease partially overlap with those in some cases of EAS. A low-dose DST is indispensable in screening for Cushing's syndrome, and $0.5 \mathrm{mg}$ dexamethasone is used in this test in Japan (2). After correcting s.D. to within $10 \%$, our previous data revealed that the $5.0 \mu \mathrm{g} / \mathrm{dl}$ cut-off had $100 \%$ sensitivity and $98 \%$ specificity for the diagnosis of Cushing's disease (4) and $100 \%$ of both for the diagnosis of EAS (5). In response to DDAVP, plasma ACTH levels were found to be significantly increased in $86 \%(19 / 22)$ of cases with Cushing's disease, especially those with microadenoma (90\%), and in $44 \%(4 / 9)$ of EAS cases (5). Other studies have shown that $30-60 \%$ of EAS cases responded to DDAVP. These results suggest that the DDAVP test cannot be used to effectively discriminate Cushing's disease from EAS.

In our previous study, plasma ACTH levels were increased by more than 1.5 -fold in response to hCRH in almost all cases of Cushing's disease, including 100\% $(62 / 62)$ and $73 \%(8 / 11)$ in cases with microadenoma and macroadenoma respectively (5). On the other hand, $27 \%$ (4/15) of EAS cases also responded to hCRH (5). Although the hCRH test may be effective for distinguishing Cushing's diseases from EAS, definitive discrimination between them using this test alone is difficult. Our previous results showed that a high-dose ( $8 \mathrm{mg}$ ) DST for diagnosing Cushing's disease was efficacious in almost $80 \%$ of cases (5). In cases of EAS, high-dose dexamethasone suppressed three of the six bronchial carcinoids and none of the nine other lung cancers (5). These results suggest that a high-dose dexamethasone test is useful for diagnosing Cushing's disease, although caution is required when interpreting the results in cases of macroadenoma or Crooke cell adenoma with Cushing's disease and in cases of bronchial carcinoid with EAS. When applying both the hCRH test and 8-mg DST together, our previous study revealed $81 \%$ sensitivity and $60 \%$ specificity in cases of Cushing's disease (5). Isidori et al. (6) reported that a low-dose DST, combined with the CRH test, obtained a higher sensitivity and specificity. As the combination of these two tests is effective for distinguishing Cushing's diseases from EAS, the data in the present case are consistent with a case of EAS.

GHRPs may have potential for screening ACTHdependent Cushing's syndrome as plasma ACTH levels are greatly increased in response to GHRP administration
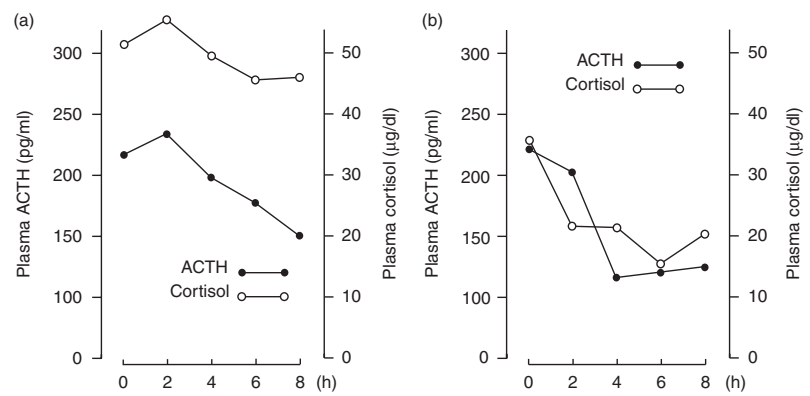

Figure 3

Changes in plasma adrenocorticotropic hormone (ACTH) and cortisol levels following treatment with (a) octreotide (100 $\mu$ g, s.c.) or (b) bromocriptine ( $2.5 \mathrm{mg}$, per os in the morning) alone (first administration). 


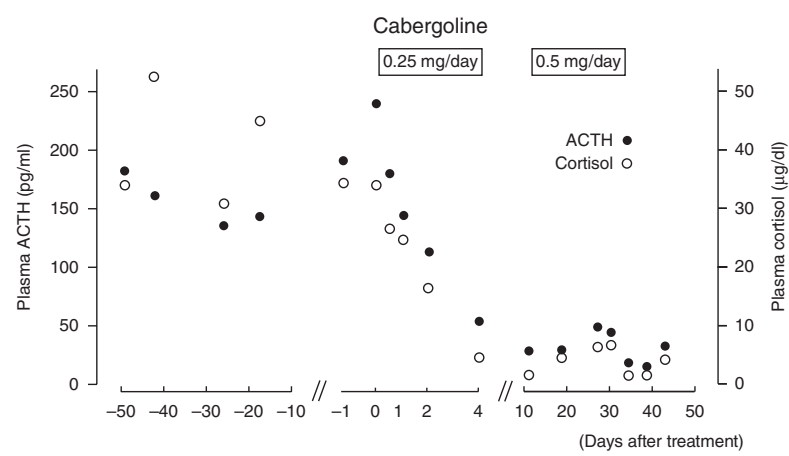

Figure 4

Clinical course of changes in plasma ACTH and cortisol levels before and after cabergoline treatment ( 2 years later).

in patients with Cushing's disease compared with normal subjects. Furthermore, GHRP2 is currently approved for clinical use in Japan. However, the mechanisms underlying the ACTH response in ACTH-dependent Cushing's syndrome remain unclear. MRI has shown high specificity in the diagnosis of Cushing's disease, and when combined with both the hCRH test and 8-mg DST, diagnostic specificity is even higher, at $90 \%$ in the presence of a pituitary adenoma. The ability of MRI to detect pituitary ACTH-secreting adenoma in patients with Cushing's disease is limited because the calculated accuracy for detecting a pituitary source of ACTH is reportedly around $60 \%$ with conventional MRI. However, the ability to detect pituitary ACTH-secreting adenoma might be improved by using a 3 Tesla magnet, which is also suitable for detecting small nonfunctioning adenoma. Cavernous or inferior petrosal sinus sampling has been validated as a highly accurate investigative tool for the differential diagnosis of ACTH-dependent Cushing's syndrome. Administration of hCRH to stimulate ACTH secretion during sampling is routinely used to elicit diagnostic gradients in cases of Cushing's disease and to improve the sensitivity of this procedure. Gradients of sinus (central) to peripheral ACTH are calculated before and after stimulation with hCRH, and Cushing's disease is diagnosed when the basal gradient is $>2$ or when the gradient after the stimulation is $>3$. The basal ratio of cavernous sinus sampling in our case was considered diagnostic for an ectopic/peripheral source of ACTH production. However, a unilateral petrosal sinus sampling failed to exclude Cushing's disease perfectly, because catheterization of the left side was unsuccessful. In our case, central ACTH levels failed to be increased after the stimulation. GHRP2 stimulation would not be interpreted, because there are no data available on its use in differential diagnosis of ACTH-dependent Cushing's syndrome. The endocrine findings in our case are mostly consistent with an ectopic ACTH-secreting tumor. EAS is most frequently caused (in $\sim 50 \%$ of all cases) by a bronchial carcinoid or small-cell lung carcinoma. However, a thymic carcinoid, gastroenteropancreatic neuroendocrine tumor, pheochromocytoma, or medullary thyroid carcinoma may also cause this syndrome. In most cases, the tumor is identified by routine imaging procedures; $\mathrm{CT}$ is a useful modality for localizing an ectopic source and, in some cases of EAS, PET scans are helpful for detecting localization. In addition, somatostatin receptor imaging, which is not available commercially in Japan, complements radiological
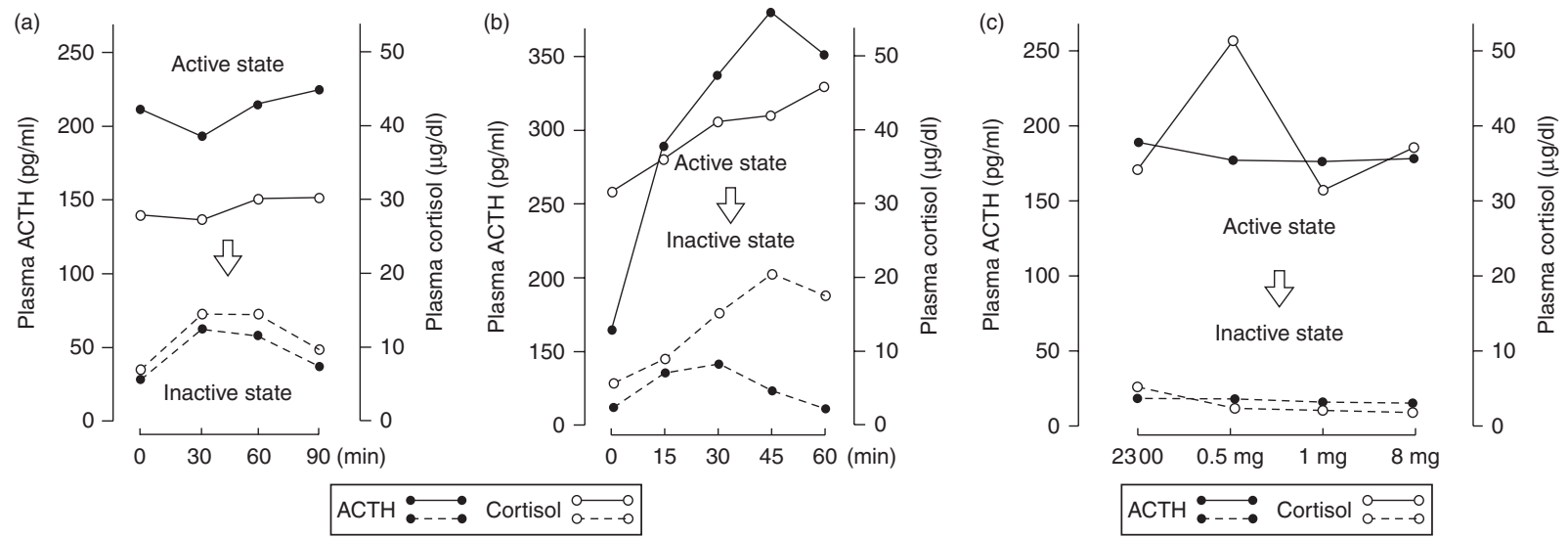

Figure 5

Hormone loading test results during active and inactive states. (a) Human corticotropin-releasing hormone test (100 $\mu$ g, i.v. bolus); (b) growth hormonereleasing peptide 2 test (100 $\mu$ g, i.v. bolus); and (c) overnight dexamethasone suppression test (per os at $2300 \mathrm{~h}$ ). ACTH, adrenocorticotropic hormone. 


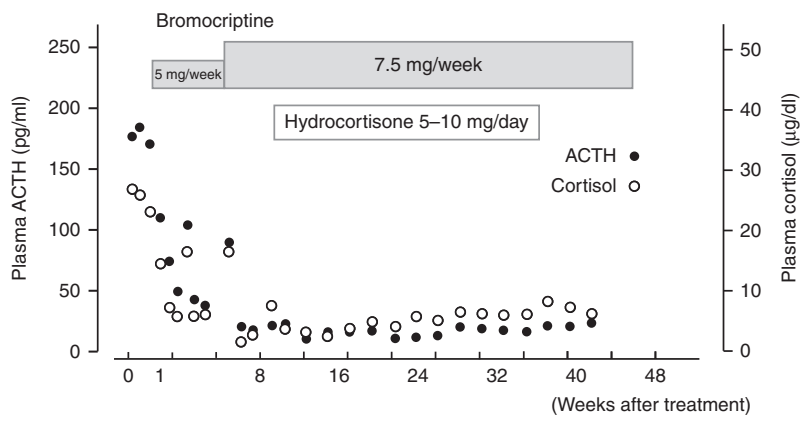

Figure 6

Clinical course of changes in plasma ACTH and cortisol levels following bromocriptine treatment.

imaging in localizing ectopic ACTH secretion sites, while glucocorticoid-lowering or -antagonizing therapy has the potential to improve the diagnostic accuracy of somatostatin receptor scintigraphy.

Despite extensive diagnostic procedures, the source of ACTH secretion remained occult in our case. Tumor excision is the primary treatment for EAS. However, when surgery is impossible, medical therapy is needed to treat hypercortisolism. The spectrum of available drugs includes adrenal-blocking agents, neuromodulatory drugs, and glucocorticoid receptor antagonists (7). Adrenal-blocking drugs suppress adrenal cortisol production by inhibiting steroidogenic enzymes (7), and prolonged remission after long-term treatment with steroidogenesis inhibitors in Cushing's syndrome has been reported in cases of EAS (8). Drugs that suppress ACTH secretion are less popular as standard treatments and may include cyproheptadine, valproic acid, cabergoline, somatostatin analogs, peroxisome proliferator-activated receptor $\gamma$ agonists, and vasopressin antagonists (9).

The first studies of dopamine agonists in Cushing's disease were performed with bromocriptine; however, the effect was not strong and was maintained over the longer term in only a small subset of cases. Better results were expected with cabergoline, which has a higher binding capacity to the dopamine type 2 receptor and a longer halflife. Pivonello et al. (10) reported six cases of ACTH-secreting carcinoids in patients who had undergone surgery, where dopamine receptors were expressed in neuroendocrine tumors associated with EAS, and cabergoline treatment was effective for controlling the cortisol excess in the subgroup of patients with EAS (10). Expression of the short isoform of the dopamine type 2 receptor, and/or coexpression of the dopamine type 4 receptor, may play a pivotal role in the effectiveness of dopamine agonists in carcinoid tumors associated with EAS (11). In the present case, shortterm initial treatment with cabergoline was effective for the long-term suppression of both ACTH and cortisol levels. Spontaneous remission in Cushing's syndrome is rare (8), and the possibility of cyclic ACTH production cannot be completely excluded. Finally, intermittent administration (three times a week) with bromocriptine, a short-acting $\left(T_{1 / 2}=2.86 \mathrm{~h}\right)$ dopamine agonist, has afforded adequate suppression of ACTH levels over the long term. Therefore, it is possible that treatment with the dopamine agonist may have deactivated ACTH secretion in this case.

The case still might have a possibility of a pituitary dysregulation of ACTH secretion that was sensitive to dopamine agonists, because the findings for Cushing's disease partially overlap with those in some cases of EAS. Although dopamine agonists deactivated ACTH secretion, it does not mean that they have also killed the occult tumor. The patient needs to be followed up by extensive examinations, including laboratory tests and imaging procedures.

In summary, a case of EAS with an unknown source of ACTH secretion was successfully controlled by administering the short-acting dopamine agonist bromocriptine.

\section{Declaration of interest}

The authors declare that there is no conflict of interest that could be perceived as prejudicing the impartiality of the research reported.

\section{Funding}

This research did not receive any specific grant from any funding agency in the public, commercial or not-for-profit sector.

Patient consent

Written informed consent has been obtained from the patient for publication of this case report.

Author contribution statement

S Sakihara is the main Endocrinologist Physician who followed the patient. $\mathrm{K}$ Kageyama is also an Endocrinologist Physician and responsible for case description. S Yamagata and $\mathrm{K}$ Terui are Endocrinologist Physicians following the patient at present. M Daimon is the present director of the Department of Endocrinology and Metabolism. T Suda is the previous director of the Department of Endocrinology and Metabolism.

\section{References}

1 Salgado LR, Fragoso MC, Knoepfelmacher M, Machado MC, Domenice S, Pereira MA \& de Mendonça BB 2006 Ectopic ACTH syndrome: our experience with 25 cases. European Journal of Endocrinology 155 725-733. (doi:10.1530/eje.1.02278) 
2 Kageyama K, Oki T, Sakihara S, Nigawara T, Terui K \& Suda T 2013 Evaluation of the diagnostic criteria for Cushing's disease in Japan. Endocrine Journal 60 127-135. (doi:10.1507/endocri.EJ12-0299)

3 Schteingart DE 2009 Drugs in the medical treatment of Cushing's syndrome. Expert Opinion on Emerging Drugs 14 661-671. (doi:10.1517/ 14728210903413522)

4 Suda T, Sakihara S, Terui K, Nigawara T, Kageyama K, Oki T \& Kuwa K. Evaluation of the diagnostic criteria for Cushing's disease by dexamethasone suppression test after considering standardization of the cortisol measurement and results of the low level measurement. Research Reports on Measures for Intractable Diseases from the Ministry of Health, Labour, and Welfare $2011 \mathrm{H} 22$ 36-40 (In Japanese).

5 Suda T, Kageyama K, Nigawara T \& Sakihara S 2009 Evaluation of diagnostic tests for ACTH-dependent Cushing's syndrome. Endocrine Journal 56 469-476. (doi:10.1507/endocrj.K08E-353)

6 Isidori AM, Kaltsas GA, Mohammed S, Morris DG, Jenkins P, Chew SL, Monson JP, Besser GM \& Grossman AB 2003 Discriminatory value of the low-dose dexamethasone suppression test in establishing the diagnosis and differential diagnosis of Cushing's syndrome.
Journal of Clinical Endocrinology and Metabolism 88 5299-5306. (doi:10.1210/jc.2003-030510)

7 Feelders RA, Hofland LJ \& de Herder WW 2010 Medical treatment of Cushing's syndrome: adrenal-blocking drugs and ketaconazole. Neuroendocrinology 92 111-115. (doi:10.1159/000314292)

8 Sharma ST \& Nieman LK 2012 Prolonged remission after long-term treatment with steroidogenesis inhibitors in Cushing's syndrome caused by ectopic ACTH secretion. European Journal of Endocrinology 166 531-536. (doi:10.1530/EJE-11-0949)

9 Miller JW \& Crapo L 1993 The medical treatment of Cushing's syndrome. Endocrine Reviews 14 443-458. (doi:10.1210/edrv-14-4-443)

10 Pivonello R, Ferone D, de Herder WW, Faggiano A, Bodei L, de Krijger RR, Lombardi G, Colao A, Lamberts SW \& Hofland LJ 2007 Dopamine receptor expression and function in corticotroph ectopic tumors. Journal of Clinical Endocrinology and Metabolism 92 65-69. (doi:10.1210/jc.2006-0728)

11 Boschetti M, Gatto F, Arvigo M, Esposito D, Rebora A, Talco M, Albertelli M, Nazzari E, Goglia U, Minuto F et al 2010 Role of dopamine receptors in normal and tumoral pituitary corticotropic cells and adrenal cells. Neuroendocrinology 92 17-22. (doi:10.1159/000314293) 